\title{
Stakeholder considerations for PrEP introduction to adolescent girls and young women: Laying the groundwork for research utilization in Tanzania
}

Population Council

Follow this and additional works at: https://knowledgecommons.popcouncil.org/departments_sbsr-hiv

Part of the Demography, Population, and Ecology Commons, Family, Life Course, and Society Commons, International Public Health Commons, Medicine and Health Commons, and the Women's Health Commons How does access to this work benefit you? Let us know!

\section{Recommended Citation}

Population Council. 2017. "Stakeholder considerations for PrEP introduction to adolescent girls and young women: Laying the groundwork for research utilization in Tanzania," Results brief. Washington, DC: Population Council. 


\section{STAKEHOLDER CONSIDERATIONS FOR PREP INTRODUCTION TO ADOLESCENT GIRLS AND YOUNG WOMEN: LAYING THE GROUNDWORK FOR RESEARCH UTILIZATION IN TANZANIA}

Adolescent girls and young women (AGYW) in Tanzania, as in many countries, are at high risk of HIV. Oral pre-exposure prophylaxis (PrEP), the use of antiretroviral medications by HIV-uninfected persons to prevent HIV, has the potential to substantially reduce HIV acquisition among AGYW as part of a comprehensive HIV prevention package, if they are able to access and use it. However, in the rollout of PrEP for AGYW, there is need to carefully examine the individual, interpersonal, structural, and sociocultural factors that may influence the provision of quality PrEP services and whether AGYW are able to make informed decisions about PrEP use. ${ }^{1}$

Introducing PrEP to AGYW in Tanzania requires information that reflects the unique

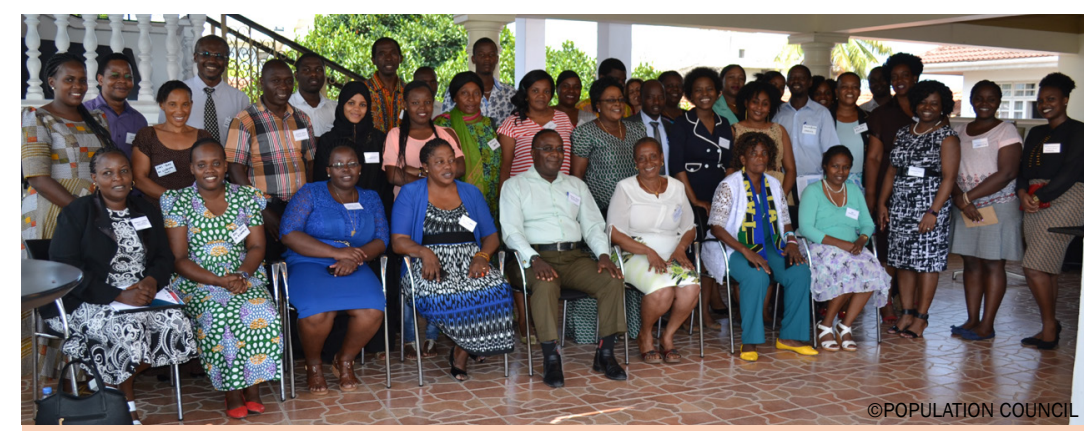

\section{PURPOSE OF PREP STUDY RESULTS BRIEFS}

As Tanzanian policymakers, programmers, and other key stakeholders consider PrEP introduction for AGYW, it is important that they are equipped with Tanzania-specific information to guide their decision-making. Throughout the study, we will produce a series of briefs that highlight preliminary and final results.

sociocultural and political environment of Tanzania. In collaboration with the National AIDS Control Programme and CSK Research Solutions Ltd, the Population Council is conducting an implementation science research study in Tanzania to build needed evidence to inform decisionmaking around PrEP introduction to AGYW aged $15-24 .{ }^{2}$ The study uses quantitative and qualitative methods to gather data from AGYW, policymakers and other stakeholders, health providers, and AGYW's parents and male partners to:

- Assess their knowledge and attitudes toward oral PrEP.

- Determine opportunities and approaches for providing PrEP.

- Identify potential facilitators and barriers to PrEP introduction and use.

\section{ENGAGING STAKEHOLDERS IN RU}

The Population Council's research utilization (RU) process involves active engagement of key stakeholders to ensure that the research is locally relevant and addresses the needs of the country. ${ }^{3}$ Our RU process engages stakeholders throughout the study to gain their insights on study questions, interpretation of the findings, and crafting programmatic recommendations and supporting their adoption within the country and beyond.

As one of the initial steps in our RU process, we held a meeting in March 2017 in Dar es Salaam, Tanzania with 35 key stakeholders from the Tanzanian Ministry of Health, the donor community, HIV service organizations, and civil society organizations. The meeting's objectives were to introduce the study to the stakeholders, to understand their views on PrEP introduction in Tanzania, and elicit their feedback on the study's aims and research questions.

Research Partners: CSK Research Solutions Ltd

Location: Dar es Salaam and Mbeya Districts

Study Duration: 2016-2018

Funder: Bill \& Melinda Gates Foundation

For more information, contact Nanlesta Pilgrim (npilgrim@ popcouncil.org), Lou Apicella (lapicella@popcouncil.org),or Catherine Kahabuka (ckahabuka@cskresearch.com). 


\begin{tabular}{|c|c|c|}
\hline & Concerns & Considerations \\
\hline 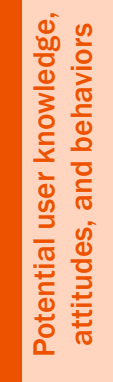 & $\begin{array}{l}\text { - Adherence: Given the existing challenges with } \\
\text { antiretroviral (ARV) adherence, how well will people } \\
\text { adhere to PrEP? } \\
\text { - Behavioral disinhibition: Will PrEP result in users } \\
\text { engaging in riskier behaviors? } \\
\text { - Side effects: More evidence is needed about the } \\
\text { long-term side effects of PrEP, especially related to } \\
\text { fertility, resistance to other ARVs, and interactions } \\
\text { with other drugs. }\end{array}$ & $\begin{array}{l}\text { Education and sensitization: Immediate and continuous } \\
\text { release of information about PrEP based on the available } \\
\text { evidence is necessary to build advocacy for PrEP introduction } \\
\text { and ultimately, end-user buy-in. }\end{array}$ \\
\hline 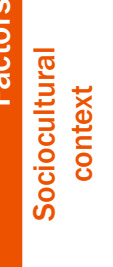 & $\begin{array}{l}\text { - Stigma and discrimination: Will providing PrEP to } \\
\text { some girls, and not all girls, result in stigma and } \\
\text { discrimination toward those girls? } \\
\text { - Demand creation: People do not use existing } \\
\text { prevention technologies, how can demand for PrEP } \\
\text { be created to encourage use and adherence? }\end{array}$ & $\begin{array}{l}\text { - Priority populations for PrEP: Vulnerable and key populations } \\
\text { should have access to PrEP but its introduction must start } \\
\text { with sero-discordant couples. } \\
\text { - Capitalize on PrEP demand to meet UNAIDS 90-90-90 goals: } \\
\text { Testing requirements with PrEP use will identify HIV+ people. } \\
\text { Health services should be prepared to link them to care. }\end{array}$ \\
\hline 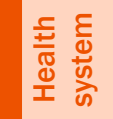 & $\begin{array}{l}\text { - Confidentiality and privacy: How can we protect } \\
\text { AGYW's privacy and confidentiality while following } \\
\text { parental consent laws for accessing health services? }\end{array}$ & $\begin{array}{l}\text { - Accessibility: Explore PrEP provision and integration into } \\
\text { existing services, such as family planning. }\end{array}$ \\
\hline 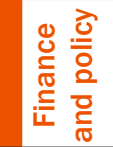 & $\begin{array}{l}\text { - Affordability: What will be the national and } \\
\text { individual cost of PrEP now and in the long term? }\end{array}$ & $\begin{array}{l}\text { Political will: PrEP introduction will be dependent on political } \\
\text { will; advocacy by key stakeholders for different institutions } \\
\text { will be necessary. }\end{array}$ \\
\hline
\end{tabular}

The table is a synthesis of participants' feedback that broadly cluster around two themes: 1) key concerns about PrEP introduction to AGYW; and 2) key considerations/ recommendations for PrEP introduction to AGYW. The two themes highlight the complex and multi-level factorsindividual, sociocultural, health systems, and finance and policy-that will influence PrEP introduction in Tanzania.

\section{INCORPORATING FEEDBACK}

Stakeholders posed additional research questions about PrEP during the meeting. Afterward, the Council refined the study's data collection instruments to incorporate a number of these questions, as follows, so that the study, within its scope, can contribute further evidence in response to the country's needs.

- How would PrEP introduction affect funding of available HIV programs or services?

- How can PrEP be effectively integrated into other health services?

- What are effective strategies to train providers in offering PrEP and supporting adherence?
- What are AGYW's views of the current formulations of PrEP under development?

- What are effective means of reminding younger girls to take PrEP?

- What impact will religion, parents, and partners have on AGYW's uptake and adherence to PrEP?

\section{NEXT STEPS}

As the study progresses, the Council will continue to engage stakeholders through release of information via study briefs and other communication channels and by bringing stakeholders together to interpret what the study results mean for PrEP introduction in Tanzania.

${ }^{1}$ Mathur, S., N. Pilgrim, and J. Pulerwitz. 2016. "PrEP introduction for adolescent girls and young women," The Lancet 3(9): e406-e408.

${ }^{2}$ Population Council. 2017. “Considerations for PrEP introduction to adolescent girls and young women: implementation science research in Tanzania," DREAMS Activity Brief. Washington, DC: Population Council.

${ }^{3}$ Project SOAR. 2016. "Project SOAR's approach to research utilization," Project SOAR. Washington, D.C.: Population Council.
POPULATION COUNCIL

Ideas. Evidence. Impact.
The Population Council confronts critical health and development issues-from stopping the spread of HIV to improving reproductive health and ensuring that young people lead full and productive lives. Through biomedical, social science and public health research in about 50 countries, the Council works with our partners to deliver solutions that lead to more effective policies, programs, and technologies to improve lives worldwide. Established in 1952 and headquartered in New York, the Council is a nongovernmental, nonprofit organization with an international board of trustees. popcouncil.org

Suggested citation: Population Council. 2017. “Stakeholder considerations for PrEP introduction to adolescent girls and young women: laying the groundwork for research utilization in Tanzania," DREAMS Tanzania Results Brief 1. Washington, DC: Population Council. 